\title{
AIDS COMO CAMPO DE PESQUISA INTERDISCIPLINAR E MULTIPROFISSIONAL.*
}

\author{
Iara de Moraes Xavier** \\ Josete Luzia Leite*** \\ Florence R. Tocantins****
}

\begin{abstract}
RESUMO: Este trabalho consta de algumas reflexões acerca da AIDS como campo de pesquisa interdisciplinar e multiprofissional. Discorre sobre os conceitos de monodisciplinaridade, multidisciplinaridade, pluridisciplinaridade, interdisciplinaridade e transdisciplinaridade. Discute a AIDS como uma doença que envolve aspectos biológicos, sociais, psicológicos e especialmente, éticos e legais. Coloca o trabalho coletivo como o grande desafio aos profissionais de saúde neste final de século, assimilando a interdisciplinaridade como tendência da modernidade.
\end{abstract}

\begin{abstract}
This study brings some considerations about AIDS as an interdisciplinary and multiprofessional field of investigation. It discourses about the conceptions of monodisciplinarity, multidisciplinarity, pluridisciplinarity, interdisciplinarity and transdisciplinarity, reasoning about the biological, social, psychological and, specially, ethical and legal aspects that involve AIDS as a disease. It considers the incorporation of interdisciplinarity as a trend of the modern world at the end of this century and a great challenge for the collective health workers.
\end{abstract}

\section{INTRODUÇÃO}

O presente trabalho não é propriamente o resultado de uma pesquisa, mas o produto de reflexões sobre a Síndrome de Imunodeficiência Adquirida como objeto de estudo.

A primeira questão que se impõe a uma investigação é a delimitação de seu objeto de estudo. Em um trabalho de pesquisa, em geral, as primeiras considerações procuram caracterizar o objeto e o conjunto de procedimentos lógicos e técnicos a serem utilizados (métodos), que se articulam a uma determinada teoria ou paradigma explicativo de uma realidade. (15)

Neste trabalho queremos enfocar a AIDS como campo de pesquisa multiprofissional e interdisciplinar.

Esta doença infecto-contagiosa, denominada AIDS, SIDA ou Síndrome de Imunodeficiência Adquirida, teve o seu primeiro reconhecimento oficial publicado no diário oficial do Center for Disease
Control do Serviço de Saúde dos Estados Unidos, em 1981, conforme relata PASTERNAK. (13)

Após essa publicação, vários simpósios a respeito do assunto foram realizados e a partir daí foi dado o nome para essa doença: AIDS (Acquired Immunodeficiency Syndrome).

Segundo BONTEMPO (2) "AIDS é um conjunto de letras que no momento vem se tornando bastante familiar e é soprada com muita angústia ... porque mata".

Das doenças como a AIDS, decorrem atos e comportamentos, fenômenos sociais, medos e idéias que são respostas a esse acaso, ou não, e que vão levar a um mundo diferente, onde se viverá com a AIDS. $\mathrm{O}$ importante é não viver num mundo fechado e mesquinho só porque existe a AIDS; essa luta deve ser levada em frente por todos aqueles que querem viver num mundo para transformá-lo, e nesse sentido a AIDS não é só um problema a ser resolvido por

* Trabalho apresentado como tema livre no $45^{\circ}$ Congresso Brasileiro de Enfermagem. Recife. PE, 28 de novembro a 3 de dezembro.

** Professora Adjunta do Departamento de Enfermagem Médico-Cirúrgica da Escola de Enfermagem Alfredo Pinto da UNI-RIO.

*** Professora Titular do Departamento de Enfermagem Médico-Cirúrgica da Escola de Enfermagem Alfredo Pinto da UNI-RIO.

**** Professora Adjunta do Departamento de Enfermagem em Saúde Pública da Escola de Enfermagem Alfredo Pinto da UNI-RIO. 
cientistas biológicos em um contexto puramente técnico.

PRATT (14) refere que o inimigo não é somente o vírus da AIDS, mas igualmente o medo, a ignorância e o preconceito.

Em recente conferência, o pesquisador da FIOCRUZ, Euclides Castilho, informou que os dados mais recentes demonstram a proletarização da AIDS no Brasil. Segundo ele, esta ocorrendo uma mudança no grupo de pessoas atingidas e nas formas de transmissão da doença.

Nós, profissionais da área da saúde, que temos como objeto concreto de trabalho. a saúde e a doença no seu âmbito social, deparamo-nos com uma questão epistemológica cnucial. Nenhuma disciplina por si só dá conta do objeto a que perseguimos, porque ele envolve ao mesmo tempo e concomitantemente, as relações sociais e o social propriamente dito, as expressões emocionais e afetivas, assim como o biológico que, em última instância, traduz, através da saúde e da doença, as condições e razões sócio-históricas e culturais dos indivíduos e gnupos.

\section{Como o biológico expressa o social?}

Como o social se realiza no biológico?

Essas são algumas das questões básicas colocadas à área da saúde ao proceder investigação científica, principalmente quando o objeto é complexo, letal e desconhecido como a AIDS.

MAUSS ${ }^{(8)}$ em seu trabalho antropológico, insiste na necessidade de encontrarmos um paradigma capaz de articular exatamente os três níveis com os quais trabalhamos - social, psicológico e biológico.

Esta declaração traz à tona, de imediato, a necessidade de uma abordagem interdisciplinar que seja capaz ao mesmo tempo de preservar a autonomia e a profundidade da pesquisa de cada área envolvida e de articular os fragmentos do conhecimento, ultrapassando e ampliando a compreensão pluridimensional dos objetos, em especial a AIDS.

A problemática interdisciplinar tem sido mais fortemente colocada a partir da década de 60 , como necessidade de transcender e atravessar o conhecimento fragmentado.

\section{O OBJETO DE ESTUDO - AIDS}

Sabemos muito sobre a AIDS e, ao mesmo tempo, sabemos muito pouco. É uma doença que veio neste final de século causar pânico em todo o mundo e, ao mesmo tempo, colocar problemas a serem investigados e demonstrar a falência de muitas estruturas que se considerava como sagradas.

A AIDS não é apenas um problema de saúde, mas sim um objeto de estudo complexo que envolve aspectos biológico, social, psicológico, e especialmente ético e legal.

A resposta a esta doença tem que ser multisetorial, abrangendo várias áreas de conhecimento.

\section{Segundo GUERRA DE MACEDO(3)}

Durante los diez últimos años hemos aprendido mucho sobre el agente causal, las manifestaciones clinicas y la epidemiologia del SIDA, apesar de los progresos logrados en el diagnóstico, medidas de control y fármacos que prolongan la vida de los pacientes, aun no contamos com um tratamiento eficaz a largo plazo ni con una vacuna. Confiamos en que pronto se dará respuesta a estos retos.

Ao nos determos na análise deste objeto de investigação, refletimos sobre a necessidade de abordá-lo observando as características da interdisciplinaridade e de forma multiprofissional.

Para homogenizarmos a questão conceitual recorremos a KENDAL e MACKINTOSH ${ }^{(5)}$ que apresentam as seguintes definições:

- monodisciplinaridade $=$ patamar inferior, especialização isolada;

- multidisciplinaridade $=$ conjunto de disciplinas que estudam simultaneamente um mesmo problema, sem que as relações entre elas sejam definidas de modo explícito;

- pluridisciplinaridade = justaposição de disciplinas, que favorece o intercâmbio e a cooperação, mas sem que haja uma real coordenação. Consiste na reunião de vários especialistas que focalizam determinado tema comum, sob seu ângulo particular;

- interdisciplinaridade = elaboração de um pressuposto comum a um conjunto de disciplinas conexas; esta hipótese serve à coordenação dos esforços realizados em todos os níveis. Procura estabelecer conexões e correspondência entre as disciplinas científicas;

- transdisciplinaridade = reagrupamento, em diferentes níveis, de todo um conjunto de disciplinas e interdisciplinas a partir de um pressuposto geral, tentativa de compreensão dos modelos e dos limites do saber humano. 
Em que pese a possibilidade de críticas e maiores considerações a respeito destas conceituações, podemos reter alguns elementos importantes para a análise do tema enfocado neste trabalho. O primeiro ponto, que nos parece essencial, é que somente a partir do nível de interdisciplinaridade podemos considerar que o grupo de pesquisa estará, efetivamente, esforçando-se na busca de um entendimento global da temática AIDS. Os patamares anteriores constituem mais ensaios de convivência, sem discussão e articulação entre os diferentes campos do conhecimento do que uma busca de novos horizontes de pesquisa.

Em segundo lugar, na interdisciplinaridade não deve haver o predomínio "a priori" de uma área do conhecimento, e sim o desenvolvimento multiprofissional da hipótese de trabalho que será o referencial comum; pressupomos o trabalho conjunto desde o início da identificação do objeto da pesquisa e de sua análise, percorrendo todas as fases da investigação. Projetos interdisciplinares permitem, desde o início, o equilíbrio entre diferentes áreas de conhecimento. Há a necessidade de uma exposição clara do objeto de pesquisa e das hipóteses que serão testadas, uma vez que nenhum dos paradigmas das diferentes áreas que participam da proposta "domina" totalmente a temática AIDS.

MINAYO ${ }^{(10)}$ afirma que a interdisciplinaridade vai desde a pura comunicação de idéias até à integração de conceitos diretores, de metodologias, de procedimentos e de dados, até a organização da pesquisa. Porém ela não pode ser vista como moda - imitação acrítica. O modismo em saúde faz com que uma tendência que poderia avançar, recue, já que não se importa, concretamente, com o que ocorre na realidade de cada país. Ao contrário, a interdisciplinaridade pode ser assumida enquanto tendência, que se sustenta no avanço do conhecimento biológico e social e da sua interação no "que fazer" da saúde, isto é, tem de estar assentada sobre um conhecimento produzido.

\section{A INTERDISCIPLINARIDADE DA AIDS}

A AIDS é uma doença que ataca o sistema imunológico do indivíduo, causada pelo vírus que hoje é chamado de vírus da imunodeficiência humana (HIV). Os primeiros casos com semelhança em diagnóstico surgiram, nos Estados Unidos e no Brasil, no início da década de 80.

A princípio acreditava-se que a AIDS fosse uma doença que atacava apenas alguns tipos de grupos, chamados de gnupos de riscos constituídos por ho- mossexuais, toxicômanos e hemofílicos. Hoje esse pensamento mudou, já que a doença começa a se alastrar para fora desses grupos específicos.

A AIDS é uma doença de grande letalidade, que tem seu quadro agravado por instalação de infecções chamadas oportunistas, que são provocadas na maior parte das vezes por germes geralmente de baixa virulência e que convivem pacificamente com as pessoas, mas que no momento em que o sistema imunológico está debilitado, como ocorre nos casos da AIDS, se desenvolvem e passam a ameaçar a vida das pessoas. (1)

Segundo o Ministério da Saúde (12) os mecanismos de transmissão do vírus HIV, responsável pela AIDS, são os que dependem do sangue ou derivados e do relacionamento sexual, através do esperma e da secreção vaginal. Outro mecanismo refere-se à amamentação de recém nato por mulher infectada.

LACAZ (6). refere que a AIDS trouxe à tona o medo e o pânico, levando a alterações significativas das interações interpessoais no contexto social em que vivemos. Vem, sobretudo, modificando comportamentos, reavendo preconceitos.

PASTERNAK (13) afirma que a primeira coisa que o paciente com AIDS sente é a perda da liberdade pessoal e o desaparecimento súbito dos amigos, parentes e dos companheiros. De repente, a pessoa está só e seus contatos humanos passam a ser feitos quase exclusivamente com a equipe de saúde que a atende. Esse mundo estrito, centrado no hospital, na doença, nos remédios e nas flutuações de seus sintomas, acaba envolvendo os médicos e os profissionais de enfermagem, especificamente estes últimos.

MENEGHIN (9) ressalta que é importante que o enfermeiro esteja atualizado, acompanhe o desenvolvimento das pesquisas e dessa forma se conscientize sobre suas possibilidades para atender o cliente.

A qualidade de vida das pessoas soropositivas esta hoje na dependência direta das pesquisas que buscam soluções para este objeto de estudo - AIDS.

Este trabalho reflete sobre a seguinte questão:

Qual a abordagem apropriada ao objeto de estudo AIDS nas pesquisas multiprofissionais?

Este objeto de estudo AIDS vem ganhando caráter especial, surpreendendo a comunidade e o meio científico pela rapidez com que se alastra e pela sua letalidade.

Segundo o Ministério da Saúde (12) em 1991 o número de casos de AIDS, quanto ao sexo, por ano 
$\therefore$ diagnóstico e razão masculino/feminino, o Brasil apresenta:

$$
\begin{aligned}
& \text { masculino }=6.591 \text { casos } \\
& \text { feminino }=1.198 \text { casos } \\
& \text { razão } M / F=6 / 1
\end{aligned}
$$

No Boletim.Epidemiológico de agosto de 1992 do Ministério da Saúde, o total de casos de AIDS notificados no Brasil é de 29.644 , sendo $87,4 \%$ do sexo masculino e $12,6 \%$ do feminino. A região sudeste apresenta o maior número de casos notificados.

Os estudos epidemiológicos vêm demonstrando uma alteração significativa no perfil desta doença, apontando para a necessidade de realizarmos pesquisas interdisciplinares, utilizando a metodologia interdisciplinar.

Segundo JAPIASSU ${ }^{(4)}$, esta metodologia é composta pelas seguintes etapas:

1. constituição de uma equipe de trabalho que se configure numa organização e estabeleça as regras metodológicas mínimas e comuns a que deverão submeter-se todos os componentes do empreendimento interdisciplinar:

2. estabelecimento dos conceitos-chaves do empreendimento comum, cuja irradiação se estenda a várias disciplinas;

3. estabelecimento da problemática da pesquisa;

4. repartição das tarefas - trata-se de determinar as "démarches" e as responsabilidades de cada um na pesquisa em comum;

5. colocar em comum todos os dados ou resultados parciais coletados pelos diferentes especialistas, permitindo assim a análise interdisciplinar.

\section{CONSIDERAÇÕES FINAIS}

Após a reflexão sobre a AIDS como um objeto de estudo que deve ser abordado interdisciplinarmente pelos profissionais de saúde que se dedicam à pesquisa, sentimos a necessidade de explicitar que entendemos por pesquisa a atividade básica das ciências na sua indagação e descoberta da realidade. Segundo MINAYO ${ }^{(11)}$ pesquisa é uma atividade e uma prática teórica de constante busca que define um processo intrinsecamente inacabado e permanente. É uma atividade de aproximação sucessiva da realidade que nunca se esgota, fazendo uma combinação particular entre teoria e dados. Porém, algumas considerações precisam ser registradas:

- nenhuma pesquisa é neutra seja ela qualitativa ou quantitativa;

- qualquer estudo da realidade, por mais objetivo que possa parecer, por mais ingênuo ou simples nas pretensões, tem a norteá-lo um arcabouço teórico que informa a escolha do objeto, todos os passos e resultados teóricos e práticos;

- nenhuma das linhas de pensamento tem o monopólio de compreensão total e completa sobre a realidade. A ela nos acedemos sempre por àproximação e usando uma frase de Lenin, citada por LUKACS, afirmamos que "a marcha do real é filosoficamente mais verdadeira e mais profunda do que nossos pensamentos mais prof undos". (7)

Concluindo, ressaltamos que a AIDS como campo de pesquisa interdisciplinare multiprofissional é o grande desafio colocado aos profissionais de saúde neste final de século. Caso se permaneça na impossibilidade de vencer este desafio, teremos de constatar que a consequência natural da ausência de comunicação entre as áreas é a solidão das nossas verdades, das nossas leituras, das nossas pesquisas.

\section{REFERÊNCIAS BIBLOGRÁFICAS}

1. Bergamo, M. et al., Procedimentos Técnicos Básicos na Prevenção da AIDS num Centro Cirúrgico de Grande Porte. Rev. Bras. de Enf., Brasilia, v.41, n.24, abr/jun, 1988.

2. BONTEMPO, M. AIDS - Esclarecimento global e uma abordagem alternativa, São Paulo.

3. GUERRA DE MACEDO, C. Boletin de la Oficina Sanitária Panamericana. v. 10, n. 5, 1991.

4. JAPIASSU, H. Interdisciplinaridade e Patologia do Saber. Rio de Janeiro: Imago Editora, 1976.
5. KENDAL, S. e MACKINTOSH, E. E. Management Problems of Polydisciplinary Environmental Research in the University Selting. In: MAB Report, n.13, Canadá, 1979.

6. LACAZ, C. da S. (coord. ) AIDS - doutrina, aspectos iatrofilosóficos e infecções oportunisticas associadas. Sarvier: São Paulo, 1979.

7. LUKACS, G. Existencialismo ou Marxismo? São Paulo: Senzala, 1967.

8. MAUSS, M. Sociologia e Antropologia. São Paulo: EPU/EDUSP, 1974. 
9. MENEGHIN, P. AIDS: Assistència de Enf ermagem e Revisão de Literatura. Rev. Paul. Enf., São Paulo, v.6, n.3, jul/set. 1986.

10. MINAYO, M.C.S. O desafio do Conhecimento: Pesquisa Qualitativa em Saude. São Paulo/Rio de Janeiro: HUCITEC - ABRASCO. 1992.

11. Interdisciplinaridade: uma questão que atravessa o saber, o poder e o mundo vivido. Medicina. Ribeirão Preto, v.24, n.2, abr/jun. 1991.
12. PRATT, R.S. AIDS: Uma Estratégia para a Assistência de Enfermagem. São Paulo: Ática. 1986.

13. MINISTÉRIO DA SAÚDE. Boletim Epidemiológica AIDS. Ano V, n. 5, Semana Epidemiológica 27 a 31/8/1992.

14. PASTERNAK, J. AIDS: verdade e mito: historia e fatos. São Paulo: Circulo do Livro, 1988.

15. ROCHA. S.M.M. e SIL.VA, G. B. da. Linhas Filosóficas e Ideológicas na Pesquisa em Enfermagem no Brasil. Rev Bras. de Enf.. Brasilia, v.40, n.4, out/dez., 1987.

Recebido para publicação em 17.12.93 